\title{
The cytokine platelet factor 4 successfully replaces bovine serum albumin for the in vitro culture of porcine embryos
}

J . M. Cambra, Cristina Martinez-Serrano, C. Maside, Heriberto Rodriguez-Martinez, E. A. Martinez, M. A. Gil and C. Cuello

The self-archived postprint version of this journal article is available at Linköping University Institutional Repository (DiVA):

http:// urn.kb.se/ resolve?urn=urn:nbn:se:liu:diva-165531

N.B.: When citing this work, cite the original publication.

Cambra, J . M., Martinez-Serrano, C., Maside, C., Rodriguez-Martinez, H., Martinez, E. A., Gil, M. A., Cuello, C., (2020), The cytokine platelet factor 4 successfully replaces bovine serum albumin for the in vitro culture of porcine embryos, Theriogenology, 148, 201-207.

https:// doi.org/ 10.1016/j.theriogenology.2019.11.009

Original publication available at:

https:/ / doi.org/ 10.1016/j.theriogenology.2019.11.009

Copyright: Elsevier (12 months)

http:// www.elsevier.com/

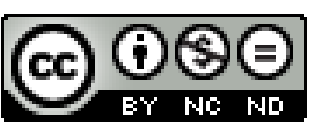


1 The cytokine platelet factor 4 successfully replaces bovine serum albumin for the 2 in vitro culture of porcine embryos.

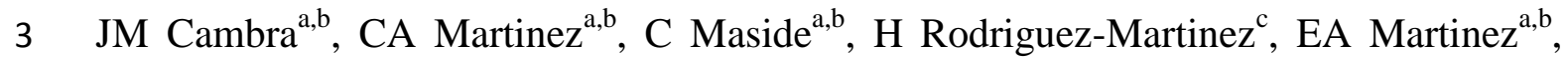
$4 \quad \mathrm{MA} \mathrm{Gil}^{\mathrm{a}, \mathrm{b}} *, \mathrm{C}$ Cuello ${ }^{\mathrm{a}, \mathrm{b}}$

5 a Department of Medicine and Animal Surgery, Faculty of Veterinary Medicine, 6 International Excellence Campus for Higher Education and Research "Campus Mare 7 Nostrum", University of Murcia, 30100, Murcia, Spain

$8{ }^{\mathrm{b}}$ Institute for Biomedical Research of Murcia (IMIB-Arrixaca), Campus de Ciencias de 9 la Salud, Carretera Buenavista s/n, 30120 El Palmar, Murcia, Spain

$10{ }^{\mathrm{c}}$ Department of Clinical \& Experimental Medicine (IKE), Linköping University, 11 Campus US, 58183, Linköping, Sweden

*Corresponding author. Maria A Gil Facultad de Veterinaria. Campus de Espinardo, 30100, Murcia, Spain

16 E-mail: mariagil@um.es

17 Tel.: +34 868884734

18 Fax: +34 868887069 


\section{ABSTRACT}

The cytokine platelet factor 4 (PF4) enhances differentiation and cell viability of different stem cells lines in vitro. This study investigated whether PF4 addition to customary pig embryo semi-defined culture media can improve their developmental outcome (Experiment 1) and ultimately replace the need for bovine serum albumin (BSA, Experiment 2). Experiment 1 added PF4 (100-1000 ng/mL, $0=$ control) to NCSU-23 with $0.4 \mathrm{mg} / \mathrm{mL}$ BSA culturing 3,430 presumptive zygotes. Experiment 2 added PF4 (100-1000 ng/mL, 0= Control-PVA) to a BSA-free medium (NCSU-23 with $0.3 \mathrm{mg} / \mathrm{mL}$ PVA) culturing 3,820 presumptive zygotes. Zygote culture in NCSU-23 with $0.4 \mathrm{mg} / \mathrm{mL}$ BSA was used as overall control. All groups of Experiment 1 displayed similar rates of day 2-cleavage (range: $65.0 \pm 10.9$ to $70.0 \pm 5.8 \%$ ); of day 7-blastocyst rates (range: $46.6 \pm 10.0$ to $56.4 \pm 8.2 \%$ ) and of total day 7-blastocyst efficiency (range: $32.3 \pm 8.3$ to $37.2 \pm 7.3 \%$ ). Addition of PF4 did not affect total cell numbers of day 7 blastocysts (range: $44.1 \pm 23.2$ to $50.5 \pm 26.4$ ). In Experiment 2, PF4 accelerated embryo development, increasing $(\mathrm{P}<0.01)$ blastocyst yield compared to $0-\mathrm{PF} 4$, and blastocyst formation by day 5 adding PF4 100-500 ng/mL (range: $29.9 \pm 7.8$ to $31.8 \pm$ 5.5\%; $\mathrm{P}<0.05)$ compared with BSA-control $(17.2 \pm 8.2 \%)$ and PF4 $1000 \mathrm{ng} / \mathrm{mL}(15.5 \pm$ $7.9 \%$ ); showing similar blastocyst rates (range: $42.0 \pm 11.5$ to $49.3 \pm 10.0 \%$ ), total efficiency $(28.0 \pm 8.2$ to $32.3 \pm 7.1 \%)$ total cell numbers (range: $42.6 \pm 19.3$ to $45.7 \pm$ 23.9) as BSA-controls. In conclusion, although PF4 did not show additive improvement under usual semi-defined, BSA-supplemented embryo media, it successfully replaced BSA sustaining porcine blastocyst production in chemically defined conditions.

Keywords: Platelet factor 4, porcine, embryo, cytokine, bovine serum albumin.

\section{INTRODUCTION}

The need to produce a large number of high-quality porcine embryos has recently acquired special importance due to the increasing demand for transgenic pigs in biomedical research. Technologies that allow the production of genetically modified pigs, such as somatic cell nuclear transfer (SCNT) using modified somatic nuclei or embryo gene editing by CRISPR-Cas 9, require a culture system that guarantees adequate development of porcine embryos in vitro. The development of an efficient embryo culture method is still a challenge. The problem is particularly acute in swine, 
where unsatisfactory culture conditions combined with a high polyspermic rate result in only $35-40 \%$ of zygotes developing to the blastocyst stage [1]. In addition, the quality of these in vitro-produced embryos is often compromised, resulting in blastocysts with approximately half of the cell number found in embryos produced in vivo [2]. Even when maturation and fertilization of oocytes occurs in vivo and the only in vitro step is the culture of zygotes to generate the blastocyst stage, the number of cells in blastocysts is reduced by half [3].

Culture media have been improved over time by modification of the energy substrates and inclusion of additives, such as amino acids, and semidefined products, including bovine serum albumin (BSA) [4]. BSA has shown embryotrophic properties [5]; however, these properties can vary from one BSA batch to another, making reproducible results difficult to obtain among laboratories or even among replicates. In addition, the biological origin of BSA entails a low but still potential risk of disease transmission [6].

There have been several attempts to remove BSA from IVP systems to develop chemically defined media. The defined culture media are usually supplemented with polyvinyl alcohol (PVA), which provides a surfactant activity similar to albumin, and other molecules with embryotrophic properties such as growth factors or cytokines $[7,8]$. Based on the similarities between porcine embryonic cells and stem cells, Spate et al. [9] recently successfully replaced the BSA in embryo culture medium with 5-(4chloro-phenyl)-3-phenyl-pent-2-enoic acid (PS48), an stimulant of the Warburg Effectlike metabolism [9] increasing outcomes. These successful results suggest that additives that have positive effects on the culture of stem cells may improve the IVP of embryos and could be potential substitutes for BSA in the culture media. To build on this point, it has been demonstrated that platelet factor $4(\mathrm{PF} 4)$, which is a peptide member of the $\mathrm{C}$ $\mathrm{X}-\mathrm{C}$ chemokine family (also known as CXCL4), enhances hematopoietic stem cell survival [10] and hematopoietic stem cell differentiation into B cell lineage cells through STAT5 activation [11]. PF4 has also shown effects on bone marrow mesenchymal stem cells, protecting these cells from radiation injury and modulating the expression of genes related to the cell cycle and inhibition of apoptosis [12]. These actions in poorly differentiated cells led us to suspect that PF4 exhibits positive effects over embryonic cells. In addition, PF4 has other important functions mainly related to coagulation activity, and in blood cells, it has a role in many functions, such as vascular inflammation, immune responses, and immune development [13-15]. There is only one 
previous report of the use of a platelet factor as an additive in porcine embryo IVP [16]; in that study, supplementation of the culture medium with platelet activating factor (PAF) enhanced the embryo development of porcine embryos after SCNT. However, there are no previous reports, to the best of our knowledge, about the use of PF4 as an additive in embryo culture media or about the replacement of BSA with platelet factors in porcine embryo IVP.

Therefore, the aims of this study were to test the effects of adding PF4 to the customary culture medium holding BSA in a porcine embryo IVP system and to investigate whether PF4 could be a suitable substitute for BSA, thus providing a chemically defined culture medium for porcine embryos.

\section{MATERIALS AND METHODS}

\subsection{Culture media}

Unless otherwise indicated, all chemicals used in this study were purchased from Sigma-Aldrich Co. (Alcobendas, Madrid, Spain). A physiological saline solution that was composed of $0.9 \mathrm{mg} / \mathrm{mL} \mathrm{NaCl}$ and $70 \mu \mathrm{g} / \mathrm{mL}$ kanamycin was used for ovaries transport. The medium used for cumulus-oocyte complexes (COCs) collection was Tyrode's Lactate (TL) medium supplemented with $10 \mathrm{mM}$ HEPES and $0.1 \mathrm{mg} / \mathrm{mL}$ polyvinyl alcohol (PVA) [17]. For COCs maturation, the medium used was Tissue culture medium (TCM) 199 (Gibco Life Technologies S.A., Barcelona, Spain) supplemented with $0.55 \mathrm{mM}$ glucose, $0.9 \mathrm{mM}$ sodium pyruvate, $75 \mu \mathrm{g} / \mathrm{mL}$ penicillin, $50 \mu \mathrm{g} / \mathrm{mL}$ streptomycin, $0.1 \mathrm{mg} / \mathrm{mL}$ PVA, $0.57 \mathrm{mM}$ cysteine and $10 \mathrm{ng} / \mathrm{mL}$ epidermal growth factor (EGF). For oocytes denudation and for washing semen samples after thawing, Dulbecco's Phosphate-buffered solution (PBS, Gibco, Grand Island, NY) supplemented with $4 \mathrm{mg} / \mathrm{mL}$ BSA was used. The basic medium used for IVF was modified Tris-buffered medium [4] supplemented with $2 \mathrm{mM}$ caffeine and $0.2 \mathrm{~g} / \mathrm{mL}$ BSA. The embryo culture medium was North Carolina State University (NCSU) 23 [18] supplemented with $0.4 \mathrm{mg} / \mathrm{mL}$ BSA. 


\subsection{Collection of cumulus-oocyte complexes}

Ovaries were obtained from prepubertal gilts at a local slaughterhouse (El Pozo S.A., Murcia, Spain) and were transported to the laboratory within 1-hour post collection in saline solution at $35^{\circ} \mathrm{C}$. After washing the ovaries in transport solution three times, medium-sized follicles (3-6 mm diameter) were sectioned with a surgical blade in TLPVA medium for COCs collection. Only COCs surrounded by at least 2 compact cumulus cell layers and with homogeneous and granulated cytoplasm were selected for in vitro maturation.

\subsection{In vitro maturation of oocytes}

Groups of 70-80 COCs were placed in each well of a four-well multidish (Nunc, Roskilde, Denmark) containing $500 \mu \mathrm{L}$ of pre-equilibrated maturation medium supplemented with $10 \mathrm{IU}$ eCG (Folligon, Intervet Inter- national B.V., Boxxmeer, the Netherlands) and 10 IU hCG (VeterinCorion, Divasa Farmavic, S.A., Barcelona, Spain) for 22 hours; this constituted the first in vitro maturation (IVM) period. The COCs were then incubated 22 hours in the same medium without hormones for the second IVM period. All incubations were performed under an oil overlay at $38.5^{\circ} \mathrm{C}$ in a humidified atmosphere of $5 \% \mathrm{CO}_{2}$ in air.

\subsection{In vitro fertilization}

After the maturation period, COCs were denuded of their cumulus cells by vortexing at 1660 rounds/min for 2 minutes in $300 \mu \mathrm{L}$ of Dulbecco's PBS supplemented with 0.1 $\mathrm{mg} / \mathrm{mL}$ hyaluronidase. Then, the denuded oocytes were washed three times with preequilibrated maturation medium and three times with pre-equilibrated fertilization medium. Oocytes with morphologicvally abnormal zona pellucida and/or cytoplasm were discarded before fertilization. After washing, groups of 40 oocytes were placed into $50 \mu \mathrm{L}$ drops of pre-equilibrated fertilization medium, covered with mineral oil and incubated for 30 minutes until spermatozoa were added.

For each replicate, two semen straws that were cryopreserved according the protocol described by Carvajal et al. [19], were thawed in a circulating water bath at $37^{\circ} \mathrm{C}$ for 20 seconds. The sperm preparation protocol used was described by Gil et al. [20]. Briefly, one $200 \mu \mathrm{L}$ pool of thawed spermatozoa was washed three times with $10 \mathrm{~mL}$ of 
160 Dulbecco's PBS, followed each time by centrifugation (1900 X g for 3 minutes). After washing, the resulting pellet was resuspended in $1 \mathrm{~mL}$ of fertilization medium. After appropriately diluting the cells, $50 \mu \mathrm{L}$ of fertilization medium containing $8 \times 10^{5}$ spermatozoa/mL was added to the drop containing the oocytes; thus, each oocyte was exposed to 1000 spermatozoa. Immediately before the last dilution, sperm motility was subjectively assessed for each replicate. Gametes were coincubated for 5 hours.

\subsection{Assessment of in vitro maturation and fertilization parameters}

To assess the fertilization parameters, a representative group of presumptive zygotes was fixed 18 hours post insemination in an acetic acid:ethanol (1:3) solution for 48 hours at room temperature, stained with $1 \%$ lacmoid in $45 \%$ (v:v) acetic acid and observed under a phase-contrast microscope at X 400 magnification. Oocytes with chromatin enclosed in a nuclear membrane or condensed in metaphase I were considered immature. Oocytes with chromatin organized in metaphase and the first polar body extruded were considered mature but not penetrated. Penetrated status was conferred when at least one male pronucleus was visible in the cytoplasm. Penetrated oocytes with only two pronuclei were considered monospermic.

The maturation rate was defined as the total number of mature and penetrated oocytes relative to the total number of oocytes fixed. The number of penetrated oocytes relative to the number of mature oocytes was the penetration rate. The monospermic rate was expressed as the ratio of monospermic oocytes to the total number of penetrated oocytes. The total efficiency of fertilization was calculated as the ratio of monospermic oocytes to the total number of oocytes inseminated.

\subsection{Embryo culture}

After coincubation, presumptive zygotes were washed three times with pre-equilibrated culture medium by mechanical pipetting to remove spermatozoa attached to the zona pellucida, and then they were transferred into a four-well multidish containing $500 \mu \mathrm{L}$ of glucose free culture medium supplemented with $0.3 \mathrm{mM}$ sodium pyruvate and 4.5 $\mathrm{mM}$ lactate for the first culture period (48 hours); there were 40 presumptive zygotes per well. 
191 For the second culture period, all embryos were removed and placed in fresh culture medium containing $5.5 \mathrm{mM}$ glucose for an additional 5 days. At day 5 of culture, embryos were supplemented with $10 \%$ fetal calf serum.

\subsection{Evaluation of embryonic development}

Embryo cleavage was assessed under a stereomicroscope at day 2 post insemination. The cleavage rate was defined as the number of developed embryos that had cleaved to the 2-to-4-cell stage out of the total number of inseminated oocytes in culture. At days 5 (Experiment 2) and 7 (Experiments 1 and 2) after insemination, blastocyst formation was assessed. Embryos with good morphology and a clear blastocoel cavity were considered blastocysts and were classified according the degree of blastocoel expansion and hatching status. The blastocyst formation rate was defined as the number of embryos that reached the blastocyst stage at days 5 and 7 out of the total number of cleaved embryos. The total efficiency of in vitro embryo production was expressed as a percentage of total oocytes inseminated that reached the blastocyst stage at day 7 . When required (Experiment 2), the total number of hatching or hatched blastocysts at day 7 as a function of the total number of blastocysts was evaluated.

\subsection{Embryo total cell count}

For the assessment of total cell number (TCN), blastocysts were fixed in PBS with 4\% paraformaldehyde at room temperature for 30 minutes. Then, the cells were washed in PBS supplemented with $0.3 \mathrm{mg} / \mathrm{mL}$ BSA and stored at $4{ }^{\circ} \mathrm{C}$ until staining was performed. These embryos were placed on a slide with a $4 \mu \mathrm{L}$ drop of Vectashield (Vector, Burlingame, CA, USA) containing $10 \mathrm{mg} / \mathrm{mL}$ Hoechst 33342, and then they were covered with a coverslip. The blastocysts were assessed using a fluorescence microscope with an excitation filter ranging from 330 to $380 \mathrm{~nm}$. The total number of nuclei that displayed blue fluorescence was counted.

\subsection{Differential embryo staining}

The number of cells in the inner cell mass (ICM) and the trophectoderm (TE) of the blastocyst was assessed using a protocol based on one described by Wydooghe et al. [21]. Blastocysts were fixed with the same procedure described above for the total cell 
number count. Fixed blastocysts were incubated overnight at $4{ }^{\circ} \mathrm{C}$ in a PBS solution with $1.5 \%$ Triton $\mathrm{X}-100$ and $0.15 \%$ Tween 20 . After this permeabilization, embryos were washed 3 times for 2 minutes each in a washing solution that consisted of PBS supplemented with $0.3 \%$ BSA. Then, blastocysts were denatured by first incubating them for 20 minutes at room temperature with a $2 \mathrm{~N} \mathrm{HCl}$ solution and then by incubating them in a $100 \mathrm{mM}$ Tris solution $(\mathrm{pH} \mathrm{8.5)}$ for 10 minutes. Denatured blastocysts were washed ( 3 times for 2 minutes in washing solution) and incubated for 5 hours in a blocking solution at $4^{\circ} \mathrm{C}$. The blocking solution consisted of PBS containing $1 \mathrm{mg} / \mathrm{mL}$ BSA, $10 \%$ normal donkey serum and $0.05 \%$ Tween 20 . After blocking, the blastocysts were washed ( 3 times for 2 minutes each in washing solution) and incubated for 1.5 days at $4{ }^{\circ} \mathrm{C}$ with a ready-to-use primary CDX2 antibody (Biogenex, San Ramon, USA) that was used at a 1:200 dilution in a commercial antibody diluent (Biogenex, San Ramon, USA). Then, the blastocysts were washed (3 times for 2 minutes each in washing solution) and transferred into a blocking solution containing diluted (1:1000) donkey anti-mouse IgG-Alexa Fluor® 568 (Invitrogen, Rockford, USA) antibody (1:1000), and they were incubated for 30 minutes at room temperature. Finally, the blastocysts were washed (3 times for 2 minutes each in washing solution) and placed in $4 \mu \mathrm{L}$ of Vectashield containing $10 \mathrm{mg} / \mathrm{mL}$ Hoechst 33342. The ICM and TE cell numbers were evaluated using a fluorescence microscope with a $536 \mathrm{~nm}$ excitation filter to count the number of trophectoderm nuclei displaying red fluorescence and a 330 to $380 \mathrm{~nm}$ excitation filter to count the total number of nuclei displaying blue fluorescence (Fig. 1).

\subsection{Experimental design}

Experiment 1. Effect of different concentrations of PF4 in NCSU-23 supplemented with $B S A$

A first experiment was conducted to determine the eventual additive effects and the optimal concentration of PF4 (human recombinant) for in vitro embryo culture. After in vitro maturation and fertilization, a total of 3430 presumptive zygotes (four replicates) were cultured in embryo culture medium supplemented with 0 (control group), 100, 200, 500 and $1000 \mathrm{ng} / \mathrm{mL}$ PF4 for 7 days. A random subset of presumptive zygotes in each replicate $(\mathrm{N}=382)$ was fixed and stained at 18 hours after insemination to assess the fertilization parameters. The remaining presumptive zygotes $(\mathrm{N}=3054)$ were cultured to evaluate the in vitro embryo development at days 2 and 7 of culture. At day 
257

7 of culture, blastocysts from each group were fixed $(\mathrm{N}=1015)$ to perform TCN assessment.

Experiment 2. Effect of different concentrations of PF4 in a BSA-free medium on embryo development and quality

In the second experiment, adding PF4 to a BSA-free culture medium was evaluated for its effect on embryonic development. A total of 3820 presumptive zygotes (six replicates) were split into six experimental groups. In one group, zygotes were cultured in NCSU-23 supplemented with $0.4 \mathrm{mg} / \mathrm{mL}$ BSA without PF4 (Control-BSA). In the other groups, BSA was replaced with $0.3 \mathrm{mg} / \mathrm{mL}$ PVA, and different concentrations of PF4 [0 (Control-PVA), 100, 200, 500 and 1000 ng/mL PF4] were added to the PVAsupplemented culture medium. At 18 hours post insemination, a representative number of presumptive zygotes $(\mathrm{N}=491)$ from each replicate were fixed and stained to assess fertilization parameters. The remaining presumptive zygotes $(\mathrm{N}=3329)$ were cultured to evaluate the in vitro embryo development at Day 2 (cleavage rate), Day 5 (blastocyst formation rate) and Day 7 (blastocyst formation and hatching rates) of culture. Some blastocysts $(\mathrm{N}=715)$ were fixed for TCN assessment or for differential staining $(\mathrm{N}=77)$.

\subsection{Statistical analysis}

Continuous variables (TCN, ICM, TE and ICM/TE) are expressed as the mean \pm SD of four (Experiment 1) or six (Experiment 2) replicates. The mean $\pm \mathrm{SD}$ of binary variables (cleavage, blastocyst rates, total efficiency and hatching rate) was obtained by calculating the variable percentage in every well of each group and in each replicate. Variables were analysed to evaluate normality by the Kolmogorov-Smirnov test, and the groups were compared using a mixed-model ANOVA followed by the Bonferroni post hoc test. Statistical analysis was performed using the IBM SPSS 24.0 Statistics package (SPSS, Chicago, IL, USA). Differences were considered significant when P < 0.05 .

\section{RESULTS}

The fertilization parameters of presumptive zygotes from the two experiments were similar and comparable to those reported previously in our laboratory, ranging from 
$76.7 \%$ to $86.2 \%, 44.1 \%$ to $62.7 \%$ and $34.0 \%$ to $43.8 \%$ for sperm penetration, monospermy and total efficiency of fertilization, respectively.

\subsection{Experiment 1}

The addition of $100,200,500$ or $1000 \mathrm{ng} / \mathrm{mL}$ of $\mathrm{PF} 4$ to the culture medium supplemented with BSA had no effect on the cleavage percentage, blastocyst formation and overall efficiency (range from $65.0 \pm 10.9 \%$ to $70.0 \pm 5.8 \%, 46.6 \pm 10.0 \%$ to $56.4 \pm$ $8.2 \%$ and $32.6 \pm 9.6 \%$ to $37.2 \pm 7.3 \%$, respectively). There were no differences between the PF4 groups and the control with regard to the TCN (range from $44.1 \pm 23.3$ to 50.5 \pm 26.4 ). These results are represented in Fig. 2 .

\subsection{Experiment 2}

This experiment was designed to evaluate the effects of PF4 in a chemically defined medium without BSA. As shown in Fig. 3, there were no differences found in the cleavage rate among groups (range: $64.3 \pm 7.4 \%$ to $72.1 \pm 5.6 \%$ ). The BSA-free medium (Control-PVA) showed the lowest $(\mathrm{p}<0.01)$ blastocyst formation rate at days 5 and 7 ( $0 \%$ and $4.6 \pm 5.2 \%$, respectively) and the lowest total efficiency $(3.4 \pm 4.2 \%)$. The addition of PF4 to this BSA-free medium significantly increased $(\mathrm{P}<0.01)$ the blastocyst formation rates at days 5 and 7 and the total efficiency. Embryonic development was accelerated in the groups of presumptive zygotes cultured in BSA-free medium supplemented with 100,200 or $500 \mathrm{ng} / \mathrm{mL}$ of PF4, which showed a higher $(\mathrm{P}<0.05)$ blastocyst formation rate at day 5 (range: $29.9 \pm 7.8$ to $31.8 \pm 5.5$ ) than the Control-BSA group $(17.2 \pm 8.2 \%)$ or the $1000 \mathrm{ng} / \mathrm{mL}$ PF4 supplemented group $(15.5 \pm$ $7.9 \%$ ). At day 7, presumptive zygotes cultured with 100, 200 or $500 \mathrm{ng} / \mathrm{mL}$ PF4 showed blastocyst formation rates and total efficiencies similar to those of presumptive zygotes cultured with BSA (range from $42.0 \pm 11.5 \%$ to $49.3 \pm 10.0 \%$, and from $28.0 \pm 8.2 \%$ to $32.3 \pm 7.1 \%$, respectively). The addition of $1000 \mathrm{ng} / \mathrm{mL}$ of PF4 to the BSA-free medium significantly $(\mathrm{P}<0.05)$ reduced the blastocyst rate $(24.4 \pm 8.1 \%)$ and total efficiency $(15.6 \pm 5.3 \%)$ of blastocyst production at day 7 compared with those of the other treatment groups and the Control-BSA group (Fig. 3). With regard to the hatching rate, none of the blastocysts from the Control-PVA group had hatched at day 7, and no differences were found among the PF4 supplemented groups and the Control-BSA group (range: $17.6 \pm 7.5$ to $23.7 \pm 12.6 \%$ ). 
322 TCN, which was used as a quality parameter of the produced blastocysts, did not vary 323 between the groups supplemented with 100, 200 and $500 \mathrm{ng} / \mathrm{mL}$ of PF4 and the control324 BSA group (range: $42.6 \pm 19.3$ to $45.7 \pm 23.9$ ). Again, as with the blastocyst production, treatment with the $1000 \mathrm{ng} / \mathrm{mL} \mathrm{PF} 4$ in BSA-free medium resulted in a smaller $(\mathrm{P}<0.05)$ number of cells $(30.7 \pm 17.8)$ than that observed in the other groups. The numbers and the distribution of cells between the inner cell mass or the trophectoderm was also similar among PF4-supplemented groups (100, 200 and $500 \mathrm{ng} / \mathrm{mL})$ and the ControlBSA group (Fig. 4). In this experiment, TCN was not determined for the Control-PVA group, and differential staining was not performed in either the Control-PVA or the $1000 \mathrm{ng} / \mathrm{mL}$ group of PF4 due to the low number of blastocysts obtained in these groups.

\section{DISCUSSION}

To the best of our knowledge, this is the first report about the effects of PF4 supplementation during in vitro porcine embryo culture. We have hereby demonstrated that PF4 could be an efficient alternative to BSA in porcine embryo culture medium. Although BSA has a beneficial effect on in vitro embryo growth [5], it is also an undefined mixture of factors, peptides and potential contaminants. For this reason, it is important to identify different replacements for BSA, which would allow reproducibility among laboratories and enhance embryo biosafety.

342 In our first experiment, the addition of PF4 during embryo culture showed a lack of effect when supplementation was performed in semidefined medium supplemented with BSA. It is known that the presence of BSA affects the results obtained with exogenous additives. Thus, it has been demonstrated that supplementation with myo-inositol [22] and hepatoma-derived growth factor (HDGF) [23] to media containing BSA did not have any evident effect. However, when these additives were tested in BSA-free media, embryo developmental competence was increased. An explanation for this lack of effect is attributed to the fact that BSA contains minute amounts of these additives per se, as it was demonstrated by Gómez et al. [23], who found that BSA preparations contained HDGF. In this sense, the presence of PF4 in BSA should not be surprising considering that PF4 is located in the $\alpha$-granules of platelets and that albumin is a blood extract. Another possible reason for the absence of an effect of PF4 in our BSA medium could be the propensity of BSA to bind to negatively charged molecules. This has been demonstrated with molecules such as heparin and glycosaminoglycans such as dextran 
sulfate [24], heparan sulfate [25], and chondroitin sulfates [26]. Under these conditions, PF4 could bind albumin, which is negatively charged, and this binding would diminish its effects on the embryos. This last theory is consistent with the results obtained in our experiments. In the absence of BSA (Experiment 2), we observed a detrimental effect with the maximum dose tested of PF4 $(1000 \mathrm{ng} / \mathrm{mL})$, which reached a toxic concentration for the embryos. However, that toxic effect was not observed at the same concentration in Experiment 1, where PF4 was added to a medium containing BSA. The binding between both substances could be responsible for the reduced PF4 availability in the medium, which would also explain the different results obtained with the BSA supplemented medium (Experiment 1) and the BSA-free medium (Experiment 2).

Our results evidence that the BSA present in the culture medium masks the effects of the PF4. Because BSA interacts with a wide range of compounds, the use of chemically defined culture conditions is the best option for further research about the effects of additives on the porcine embryo development in vitro.

In the absence of BSA, our chemically defined medium containing PVA did not have the ability to support blastocyst formation. However, under those defined culture conditions, the addition of PF4 clearly improved the in vitro blastocyst formation outcomes. Our results thus demonstrate that BSA can be successfully replaced by PVA together with 100, 200 and $500 \mathrm{ng} / \mathrm{mL}$ PF4 supplementation. A similar finding was reported in bovine by Eckert and Niemann [27], who demonstrated that platelet-derived growth factor (PDGF) added to a PVA-based medium free of BSA and serum could still sustain bovine in vitro embryo development to the blastocyst stage, and these results are similar to those achieved with the traditional culture medium supplemented with serum. How PF4 exerts it effects on the embryos is yet unknown, but it has been reported that PF4 treatment of mesenchymal cells enhanced proliferation and apoptosis inhibition by the induction of differential expression of genes related to DNA reparation and cell cycle modulation [12]. In addition, PF4 supplementation during culture is involved in an increase in hematopoietic progenitor cell survival and differentiation. This particular effect was attributed to an increase in the proportion of phosphorylated STAT5 proteins in the presence of $100 \mathrm{ng} / \mathrm{mL}$ PF4 [11]. The phosphorylation of STAT5 proteins is related to the activation of metabolic pathways involved in growth and cell development, such as the PI3K-Akt pathway [28,29] and the Ras-MAPK pathway [30], which has been previously reported to improve the development of in vitro porcine 
390

391

392

393

394

395

396

397

398

399

400

401

402

403

404

405

406

407

408

409

410

411

412

413

414

415

416

417

418

419

420

421

422

embryos [9]. The potential activation of different genes and/or pathways and the modification of proteins in the embryos produced by PF4 exposure may be responsible for the differences in blastocyst production among the control-PVA and PF4supplemented groups observed in Experiment 2. Further studies are however needed to determine which pathways are involved.

Another interesting point to consider is that in Experiment 2, we did not find differences in the cleavage rate between the PF4 and control groups, regardless of the culture medium used (defined or semidefined). However, the culture conditions certainly affected subsequent embryo development towards the blastocyst stage. Our results are similar to those previously reported that compared defined and semidefined media [22,31] and indicated that the requirements for the first embryo division are different than those for blastulation. In Experiment 2, we also found that supplementation with 100, 200 and $500 \mathrm{ng} / \mathrm{mL}$ PF4 increased the number of blastocysts at day 5 compared with the number observed in our conventional culture medium with BSA. This early blastocyst development may reflect a better embryo quality and a higher subsequent embryo developmental potential [32,33].

The values for the blastocyst formation rate and hatching rate at day 7, the TCN and the ratio of ICM cells to TE cells in the blastocysts produced in the medium supplemented with 100, 200 and $500 \mathrm{ng} / \mathrm{mL} \mathrm{PF} 4$ were all similar to those of embryos produced using the BSA-supplemented culture medium. These results suggest that presumptive zygotes cultured in the defined medium supplemented with PF4 have a potential to develop into blastocysts similar to that of zygotes cultured in the presence of BSA.

\section{CONCLUSIONS}

In conclusion, although PF4 supplementation failed to improve our usual semidefined culture medium containing BSA, it successfully replaced BSA when added at 100, 200 or $500 \mathrm{ng} / \mathrm{mL}$, sustaining porcine blastocyst production in chemically defined conditions.

\section{Acknowledgments}

The authors are grateful to Moises Gonzalvez and Jose M Martinez for their assistance throughout this work. The authors are grateful to AIM Iberica (Murcia, Spain) and El Pozo (Murcia, Spain) for supplying the boar ejaculates and the ovaries, respectively, 
used in this study. We thank the Seneca Foundation, Murcia, Spain (Saavedra Fajardo Program; 20027/SF/16) for funding support of C Maside and the Ministry of Economy and Competitiveness (Madrid, Spain) for its grant-based support of CA Martinez and JM Cambra (BES-2013-064087 and BES-2016-077869, respectively).

\section{Funding}

This study was supported by the Ministry of Science, Innovation and UniversitiesFEDER (RTI2018-093525-B-I00), Madrid, Spain, the Seneca Foundation (19892/GERM/15), Murcia, Spain, and the Research Council FORMAS, (Project 201700946), Stockholm, Sweden.

\section{Role of the funding source}

Funding sources did not have any involvement in the study design, in the collection, analysis and interpretation of data, in the writing of the report, or in the decision to submit the article for publication.

\section{Author contributions}

C Cuello, MA Gil, EA Martinez and JM Cambra conceived and designed the study. C Cuello and MA Gil oversaw the experimentation. JM Cambra, CA Martinez, C Maside, EA Martinez, C Cuello and MA Gil performed the experiments. JM Cambra, EA Martinez, H Rodriguez-Martinez, C Cuello and MA Gil analyzed and interpreted the data. JM Cambra wrote the manuscript. CA Martinez, EA Martinez, H RodriguezMartinez, C Cuello and MA Gil revised and discussed the manuscript. All authors read and approved the manuscript for publication. EA Martinez, H Rodriguez-Martinez and MA Gil secured the funding.

\section{Declaration of interest}

None of the authors have any conflicts of interest to declare. 


\section{REFERENCES}

[1] Gil MA, Martinez CA, Nohalez A, Parrilla I, Roca J, Wu J, et al. Developmental competence of porcine genome-edited zygotes. Mol Reprod Dev 2017. doi:10.1002/mrd.22829.

[2] Macháty Z, Day BN, Prather RS. Development of early porcine embryos in vitro and in vivo. Biol Reprod 1998;59:451-5. doi:10.1095/biolreprod59.2.451.

[3] Almiñana C, Gil MA, Cuello C, Parrilla I, Caballero I, Sanchez-Osorio J, et al. Capability of frozen-thawed boar spermatozoa to sustain pre-implantational embryo development. Anim Reprod Sci 2010;121:145-51. doi:10.1016/j.anireprosci.2010.05.004.

[4] Abeydeera LR, Day BN. In vitro penetration of pig oocytes in a modified Trisbuffered medium: effect of BSA, caffeine and calcium. Theriogenology 1997;48:537-44.

[5] Gajda B, Bryla M, Smorag Z. Effects of protein source, vitamin E and phenazine ethosulfate on developmental competence and quality of porcine embryos cultured in vitro. Folia Biol (Praha) 2008;56:57-63.

[6] Hasler JF. Synthetic media for culture, freezing and vitrification of bovine embryos. Reprod Fertil Dev 2010;22:119-25. doi:10.1071/RD09224.

[7] Neira JA, Tainturier D, Peña MA, Martal J. Effect of the association of IGF-I, IGF-II, bFGF, TGF- $\beta 1$, GM-CSF, and LIF on the development of bovine embryos produced in vitro. Theriogenology 2010;73:595-604. doi:10.1016/j.theriogenology.2009.10.015.

[8] Moreno D, Neira A, Dubreil L, Liegeois L, Destrumelle S, Michaud S, et al. In vitro bovine embryo production in a synthetic medium: Embryo development, cryosurvival, and establishment of pregnancy. Theriogenology 2015;84:1053-60. doi:10.1016/j.theriogenology.2015.04.014.

[9] Spate LD, Brown A, Redel BK, Whitworth KM, Prather RS. PS48 can replace bovine serum albumin in pig embryo culture medium, and improve in vitro embryo development by phosphorylating AKT. Mol Reprod Dev 2015;82:31520. doi:10.1002/mrd.22474.

[10] Han ZC, Lu M, Li J, Defard M, Boval B, Schlegel N, et al. Platelet Factor 4 and Other CXC Chemokines Support the Survival of Normal Hematopoietic Cells and Reduce the Chemosensitivity of Cells to Cytotoxic Agents. Blood 
1997;89:2328-35.

[11] Field DJ, Aggrey-Amable AA, Blick SK, Ture SK, Johanson A, Cameron SJ, et al. Platelet factor 4 increases bone marrow B cell development and differentiation. Immunol Res 2017. doi:10.1007/s12026-017-8951-x.

[12] Chen J-J, Gao Y, Tian Q, Liang Y-M, Yang L. Platelet factor 4 protects bone marrow mesenchymal stem cells from acute radiation injury. Br J Radiol 2014;87:20140184. doi:10.1259/bjr.20140184.

[13] Zucker MB, Katz IR. Platelet factor 4: production, structure, and physiologic and immunologic action. Proc Soc Exp Biol Med 1991;198:693-702.

[14] von Hundelshausen P, Petersen F, Brandt E. Platelet-derived chemokines in vascular biology. Thromb Haemost 2007;97:704-13.

[15] Kowalska MA, Rauova L, Poncz M. Role of the platelet chemokine platelet factor 4 (PF4) in hemostasis and thrombosis. Thromb Res 2010;125:292-6. doi:10.1016/j.thromres.2009.11.023.

[16] Lee SH, Kim DY, Nam DH, Hyun SH, Lee GS, Kim HS, et al. Role of messenger RNA expression of platelet activating factor and its receptor in porcine in vitro-fertilized and cloned embryo development. Biol Reprod 2004;71:919-25. doi:10.1095/biolreprod.103.026138.

[17] Martinez EA, Angel MA, Cuello C, Sanchez-Osorio J, Gomis J, Parrilla I, et al. Successful non-surgical deep uterine transfer of porcine morulae after 24 hour culture in a chemically defined medium. PLoS One 2014. doi:10.1371/journal.pone.0104696.

[18] Petters RM, Wells KD. Culture of pig embryos. J Reprod Fertil Suppl 1993;48:61-73.

[19] Carvajal G, Cuello C, Ruiz M, Vazquez JM, Martinez EA, Roca J. Effects of centrifugation before freezing on boar sperm cryosurvival. J Androl 2004;25:389-96.

[20] Gil MA, Roca J, Cremades T, Hernandez M, Vazquez JM, Rodriguez-Martinez $\mathrm{H}$, et al. Does multivariate analysis of post-thaw sperm characteristics accurately estimate in vitro fertility of boar individual ejaculates? Theriogenology 2005;64:305-16. doi:10.1016/j.theriogenology.2004.11.024.

[21] Wydooghe E, Vandaele L, Beek J, Favoreel H, Heindryckx B, De Sutter P, et al. Differential apoptotic staining of mammalian blastocysts based on double immunofluorescent CDX2 and active caspase-3 staining. Anal Biochem 
2011;416:228-30. doi:10.1016/j.ab.2011.05.033.

[22] Lim KT, Jang G, Ko KH, Lee WW, Park HJ, Kim JJ, et al. Improved in vitro bovine embryo development and increased efficiency in producing viable calves using defined media. Theriogenology 2007;67:293-302. doi:https://doi.org/10.1016/j.theriogenology.2006.07.011.

[23] Gómez E, Carrocera S, Martin D, Sánchez-Calabuig MJ, Gutiérrez-Adán A, Murillo A, et al. Hepatoma-derived growth factor: Protein quantification in uterine fluid, gene expression in endometrial-cell culture and effects on in vitro embryo development, pregnancy and birth. Theriogenology 2017;96:118-25. doi:10.1016/j.theriogenology.2017.04.008.

[24] Loscalzo J, Melnick B, Handin RI. The interaction of platelet factor four and glycosaminoglycans. Arch Biochem Biophys 1985;240:446-55.

[25] Witt DP, Lander AD. Differential binding of chemokines to glycosaminoglycan subpopulations. Curr Biol 1994;4:394-400. doi:https://doi.org/10.1016/S09609822(00)00088-9.

[26] Petersen F, Bock L, Flad HD, Brandt E. Platelet factor 4-induced neutrophilendothelial cell interaction: involvement of mechanisms and functional consequences different from those elicited by interleukin- 8 . Blood 1999;94:4020-8.

[27] Eckert J, Niemann H. Effects of platelet-derived growth factor (PDGF) on the in vitro production of bovine embryos in protein-free media. Theriogenology 1996;46:307-20. doi:10.1016/0093-691x(96)00187-2.

[28] Santos SC, Lacronique V, Bouchaert I, Monni R, Bernard O, Gisselbrecht S, et al. Constitutively active STAT5 variants induce growth and survival of hematopoietic cells through a PI 3-kinase/Akt dependent pathway. Oncogene 2001;20:2080-90. doi:10.1038/sj.onc.1204308.

[29] Schmidt JW, Wehde BL, Sakamoto K, Triplett AA, Anderson SM, Tsichlis PN, et al. Stat5 Regulates the Phosphatidylinositol 3-Kinase/Akt1 Pathway during Mammary Gland Development and Tumorigenesis. Mol Cell Biol 2014;34:136377. doi:10.1128/MCB.01220-13.

[30] Nyga R, Pecquet C, Harir N, Gu H, Dhennin-Duthille I, Regnier A, et al. Activated STAT5 proteins induce activation of the PI 3-kinase/Akt and Ras/MAPK pathways via the Gab2 scaffolding adapter. Biochem J 2005;390:359-66. doi:10.1042/BJ20041523. 
554 [31] Krisher RL, Lane M, Bavister BD. Developmental competence and metabolism

555

556

557

558

559

560

561

562

563

564

565

566

567

568

569

570

571

572

573

574

575

576

577

578

579

580

581

582

583

584

585

586 of bovine embryos cultured in semi-defined and defined culture media. Biol Reprod 1999;60:1345-52.

[32] Desai N, Goldberg JM, Austin C, Falcone T. Are cleavage anomalies, multinucleation, or specific cell cycle kinetics observed with time-lapse imaging predictive of embryo developmental capacity or ploidy? Fertil Steril 2018;109:665-74. doi:10.1016/j.fertnstert.2017.12.025.

[33] Ho JR, Arrach N, Rhodes-Long K, Salem W, McGinnis LK, Chung K, et al. Blastulation timing is associated with differential mitochondrial content in euploid embryos. J Assist Reprod Genet 2018;35:711-20. doi:10.1007/s10815018-1113-9.

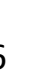

7

8

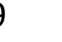


587

588

589

590

591

592

593

594

595

596

597

598

599

600

601

602

603

604

605

606

607

608

609

610

611

612

613

614

615

\section{Figure legends}

Figure 1. Differential staining of a day 7 blastocyst produced under defined conditions (NCSU-23 supplemented with $0.3 \mathrm{mg} / \mathrm{mL}$ PVA and $100 \mathrm{ng} / \mathrm{mL}$ of platelet factor 4 , PF4). All cells were stained with Hoechst (A); Trophoectoderm cells were stained with anti-CDX2 (B); Merged images show inner cell mass and trophectoderm cells displaying blue and purple fluorescence, respectively $(C)$.

Figure 2. Cleavage rate, blastocyst formation rate at day 7, total efficiency and total cell number (TCN) in day 7 blastocysts obtained after embryo culture in NCSU-23 with 0.4 $\mathrm{mg} / \mathrm{mL}$ BSA supplemented with 0 [Control-BSA $(\mathrm{N}=603)$ ], $100(\mathrm{~N}=595), 200(\mathrm{~N}=617)$, $500(\mathrm{~N}=620)$ or $1000(\mathrm{~N}=619) \mathrm{ng} / \mathrm{mL}$ of platelet factor $4(\mathrm{PF} 4)$. Data are expressed as the mean $\pm \mathrm{SD}$ (four replicates).

Figure 3. Cleavage rate, blastocyst formation rate at day 5 (D5), blastocyst formation rate at day 7 (D7), total efficiency and total cell number (TCN) in day 7 blastocysts obtained after embryo culture in a chemically defined culture medium NCSU-23 with $0.3 \mathrm{mg} / \mathrm{mL}$ PVA supplemented with 0 [Control-PVA, (N=547)], $100(\mathrm{~N}=551), 200$ $(\mathrm{N}=558), 500(\mathrm{~N}=558)$ or $1000(\mathrm{~N}=554) \mathrm{ng} / \mathrm{mL}$ of platelet factor $4(\mathrm{PF} 4)$. Control-BSA embryos were cultured under semidefined conditions [NCSU-23 with $0.4 \mathrm{mg} / \mathrm{mL}$ BSA $(\mathrm{N}=561)]$. Data are expressed as the mean \pm SD (six replicates). Different letters shown within the same variable indicate significant differences $(\mathrm{P}<0.05)$.

Figure 4. Total cell number (TCN), number of trophectoderm (TE) cells, number of inner cell mass (ICM) cells and ratio of ICM cells to TE cells of day 7 blastocysts produced using a chemically defined culture medium (NCSU-23 with $0.3 \mathrm{mg} / \mathrm{mL}$ PVA) supplemented with $100(\mathrm{~N}=17), 200(\mathrm{~N}=20)$ or $500(\mathrm{~N}=18) \mathrm{ng} / \mathrm{mL}$ of platelet factor 4 (PF4). Control-BSA blastocysts were produced under semidefined conditions [NCSU23 with $0.4 \mathrm{mg} / \mathrm{mL}$ BSA $(\mathrm{N}=22)$ ]. Data are expressed as the mean $\pm \mathrm{SD}$ (six replicates). 
A

B

C
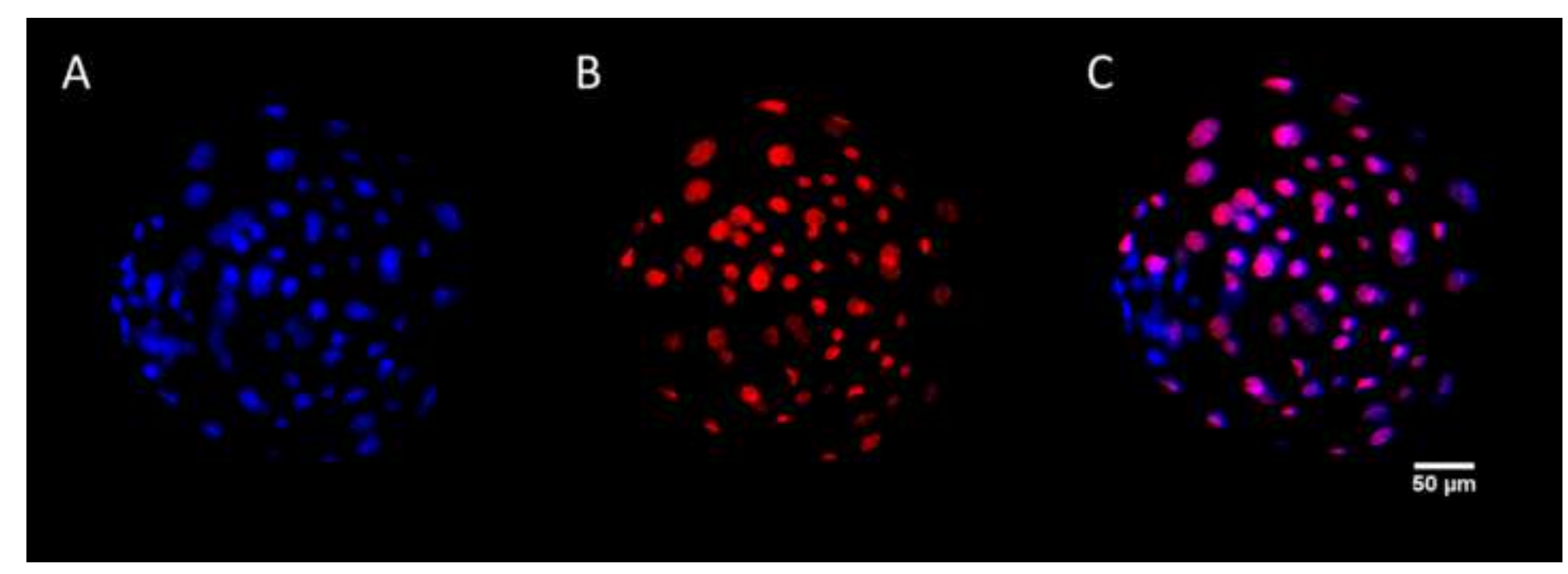

$\overline{50 \mu m}$ 


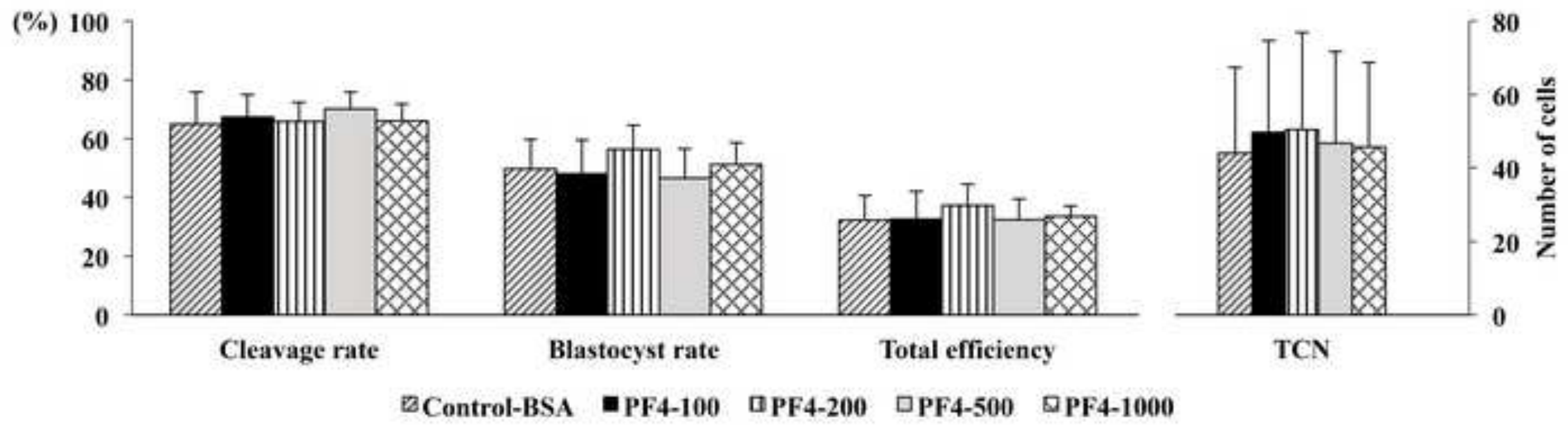


(\%) 10

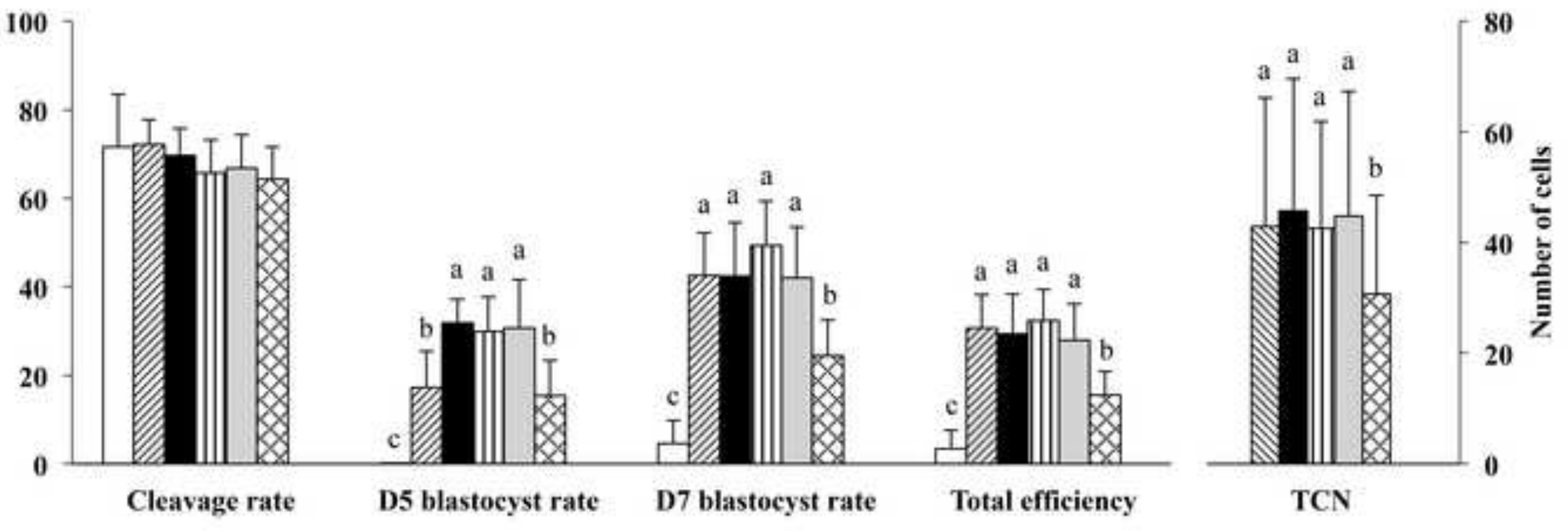

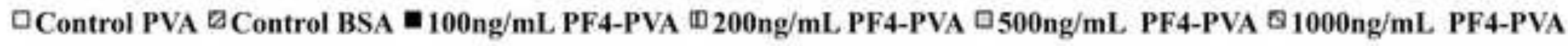




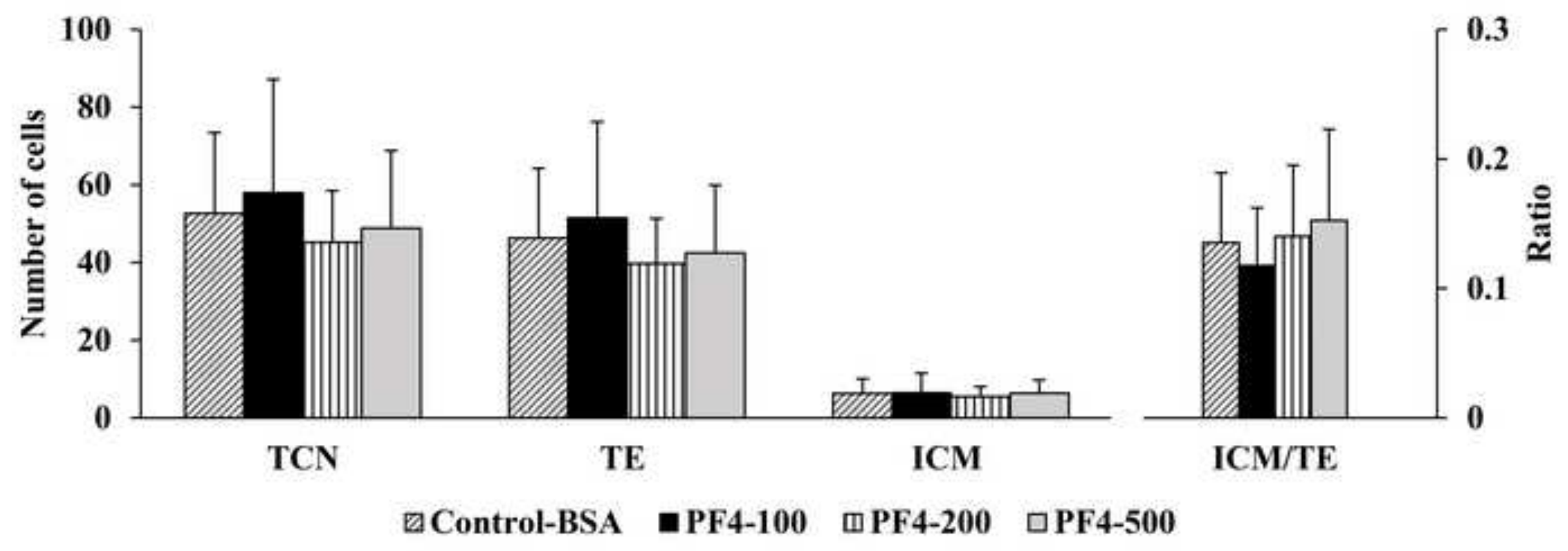

